\title{
PERANCANGAN SISTEM INFORMASI PEMETAAN DAN PEMANTAUAN DAERAH ALIRAN SUNGAI (DAS) TONDANO DI KOTA MANADO BERBASIS SMS-GATEWAY
}

\author{
Arifializevic M. Maribondang ${ }^{1)}$, Hans Wowor ${ }^{2)}$, Stanley Karouw ${ }^{3)}$ \\ ${ }^{1,2,3}$ Program Studi Teknik Informatika, Fakultas Teknik, Universitas Sam Ratulangi \\ Jl. Kampus UNSRAT Bahu, Manado, 95115 \\ Telp : (0431) 852959, Fax : (0431) 823705 \\ E-mail : arie@vandalizm.web.id ${ }^{1)}$, hanswowor@unsrat.ac.id ${ }^{2)}$, stanley.karouw@unsrat.ac.id ${ }^{3)}$
}

\begin{abstract}
Abstrak
Sistem Informasi Pemetaan dan Pemantauan DAS Tondano di Kota Manado dimaksudkan untuk mengumpulkan, menyimpan dan mengelola data terkait kondisi DAS Tondano, terutama menyangkut kondisi ketinggian air.

Panduan proses dan aktivitas perancangan sistem ini mengacu pada pendekatan agile dengan metodologi Disciplined Agile Delivery (DAD). Pemodelan sistem menggunakan UML 2.0. Perancangan pengembangan sistem menggunakan Web dan Mobile Web, menggunakan GoogleMaps API sebagai peta online, mendukung fitur SMS Gateway untuk mengirim juga menerima data dan MySQL sebagai basis data.

Sistem informasi ini akan membantu masyarakat dalam memantau kondisi DAS Tondano di Kota Manado.
\end{abstract}

Kata kunci: Disciplined Agile Delivery, UML, Google Maps API, MySQL, SMS Gateway, Web, Mobile Web

\section{PENDAHULUAN}

Banjir bandang di Manado 15 Januari 2014 akibat meluapnya DAS (Daerah Aliran Sungai) Tondano yang mengakibatkan 19 orang tewas, kerusakan rumah 10.844 unit, 2.091 jiwa mengungsi serta merusak beberapa infrastruktur lainnya dan di perkirakan kerugian mencapai 1,8 triliun rupiah (data bnpb.go.id[1], diakses 7 Mei 2014). Banyak pendapat tentang dampak banjir bandang ini, salah satunya yaitu kurangnya informasi ke masyarakat mengenai kondisi DAS Tondano di Kota Manado pada saat itu, sehingga masyarakat pada umumnya tidak mengetahui kalau air sungai sudah meluap. Maka dari itu penelitian ini akan membangun sebuah produk aplikasi berbasis web dilengkapi dengan fitur SMS Gateway sebagai pemantauan kondisi DAS Tondano di Kota Manado untuk menjawab permasalahan yang ada.

\section{LANDASAN TEORI}

\subsection{Sistem Informasi Berbasis SMS-Gateway}

Short Message Service (SMS)[2] merupakan sebuah layanan yang banyak diaplikasikan pada sistem komunikasi tanpa kabel, memungkinkan dilakukannya pengiriman pesan dalam bentuk teks. SMS didukung oleh GSM (Global System For Mobile Communication), TDMA (Time Division Multiple Access), CDMA (Code Division Multiple Access) yang berbasis pada telepon seluler yang saat ini banyak digunakan. SMS (Short Message Service) adalah merupakan salah satu layanan pesan teks yang dikembangkan dan distandarisasi oleh suatu badan yang bernama ETSI (European Telecommunication Standards Institute) sebagian dari pengembangan GSM (Global System for Mobile Communication) Phase 2, yang terdapat pada dokumentasi GSM 03.40 dan GSM 03.38. Fitur SMS ini memungkinkan perangkat Stasiun Seluler Digital (Digital Cellular Terminal, seperti Ponsel) untuk dapat mengirim dan menerima pesan-pesan teks dengan panjang sampai dengan 160 karakter melalui jaringan GSM.

Dalam beberapa tahun terakhir[3], SMS telah membuat dampak besar pada cara kita berkomunikasi. Orang lebih memilih SMS untuk berkomunikasi, tidak hanya untuk pesan tetapi juga untuk pertukaran informasi. Pengguna ponsel mengirim informasi yang diperlukan melalui SMS ke gateway ponsel yang meneruskan ke 
aplikasi. Mengingat informasi pengguna yang disediakan, aplikasi secara otomatis menghasilkan sebuah query yang tepat dalam pengolahan data.

\subsection{Sistem Kerja SMS}

Terdiri dari 7 bagian pending dalam sistem kerja SMS[4]:

- AT Command: AT Command digunakan untuk berkomunikasi dengan terminal melalui serial port pada komputer.

- SMS Center (SMSC): Ini merupakan pusat kirim dan terima pesan. Tujuannya menampung semua pengiriman SMS, kemudian mengirimkan pesan ke tujuan (sebagai penghubung).

- PDU: Data yang mengalir ke atau dari SMSC harus berbentuk PDU (Protocol Data Unit). PDU berisi bilangan-bilangan heksadesimal yang mencerminkan bahasa I/O. PDU terdiri dari beberapa header yang berbeda pada saat kirim SMS ke SMSC dengan saat SMS diterima dari SMSC.

\subsection{Disciplined Agile Delivery (DAD)}

Disciplined Agile Delivery Lifecycle[5] terdiri dari 3 tahapan pengembangan, yaitu:

1) Inception

Tahap membentuk sebuah lingkup proyek (project scope) atau tim, mengidentifikasikan rencana awal dalam proyek yang akan dijalankan, mempersiapkan lingkungan pengerjaan proyek serta mengestimasi biaya dan penjadwalan. Proses iterasi dilakukan satu kali. Dan artifak yang dihasilkan adalah dokumen vision, software project plan.

2) Construction

Tahap aktivitas memodelkan dan membangun sistem aplikasi. Proses iterasi dilakukan dua hingga delapan kali. Artifak yang dihasilkan adalah arsitektur sistem (snapshot), use case (snapshot), activity diagram (snapshot), class diagram (snapshot), sequence diagram (snapshot), source code, code documentation.

3) Transition

Tahap aktivitas menguji sistem (integration sistem dan user testing), mereview kembali sistem aplikasi dan menginstalasi sistem aplikasi. Proses iterasi dapat dilakukan satu hingga dua kali. Artifak yang dihasilkan adalah dokumen spesifikasi sistem dan testing aplikasi.

\section{METODOLOGI PENETILIAN}

3.1 Kerangka Penelitian

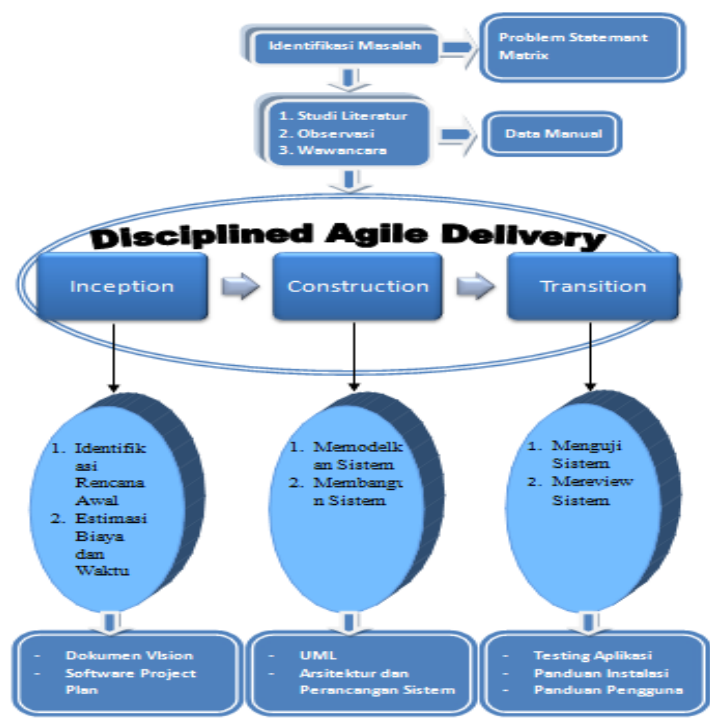

Gambar 1. Kerangka Penelitian 
Dalam Gambar 1 mencakup bagian penting yang dilakukan dalam penelitian ini, yaitu:

- Data Manual

Input: Studi Literatur, Observasi dan Wawancara

Proses: Melakukan pengumpulan data

Output: Data manual yang dibutuhkan untuk merancang bangun sistem

- Metodologi DAD, terdiri dari 3 tahap yang terstruktur dan saling bergantung disetiap tahap, yaitu Tahap Inception, Tahap Construction, Tahap Transition.

Berikut ini proses perancangan sistem dengan menggunakan metodologi DAD:

1. Tahap Inception

Tujuan dari tahap awal atau tahap inception ini yaitu menderfinisikan batasan-batasan lingkungan proyek, estimasi kasar terhadap biaya dan waktu mendefinisikan resiko, menentukan kelayakan serta mempersiapkan lingkungan pengerjaan proyek.

\begin{tabular}{|c|c|}
\hline The problem of & $\begin{array}{l}\text { 1. Kurangnya informasi kepada masyarakat Kota Manado mengenai DAS } \\
\text { Tondano } \\
\text { 2. Informasi ketinggian air tidak diperoleh dalam waktu singkat }\end{array}$ \\
\hline Affects & $\begin{array}{l}\text { Tidak mengetahui kalau air sungai sudah meluap, sehingga tidak sempat } \\
\text { melakukan antisipasi }\end{array}$ \\
\hline $\begin{array}{l}\text { The impact of } \\
\text { which is }\end{array}$ & Beberapa orang tewas, barang-barang berharga hilang dan rusak \\
\hline $\begin{array}{l}\text { A successful } \\
\text { solution would be }\end{array}$ & $\begin{array}{l}\text { Merancang bangun sistem informasi pemetaan dan pemantauan DAS } \\
\text { Tondano di Kota Manado berbasis web sehingga dapat mempermudah } \\
\text { masyarakat Kota Manado untuk mengetahui informasi aliran sungai secara } \\
\text { cepat dan tepat dalam mitigasi banjir bandang }\end{array}$ \\
\hline
\end{tabular}

Tabel 1. Problem Statement Matrix

\section{Tahap Construction}

Tujuan dari tahap kedua atau tahap construction ini yaitu memodelkan dan membangun sistem aplikasi. Berikut adalah pemodelan sistem yang dilakukan dalam penelitian ini.

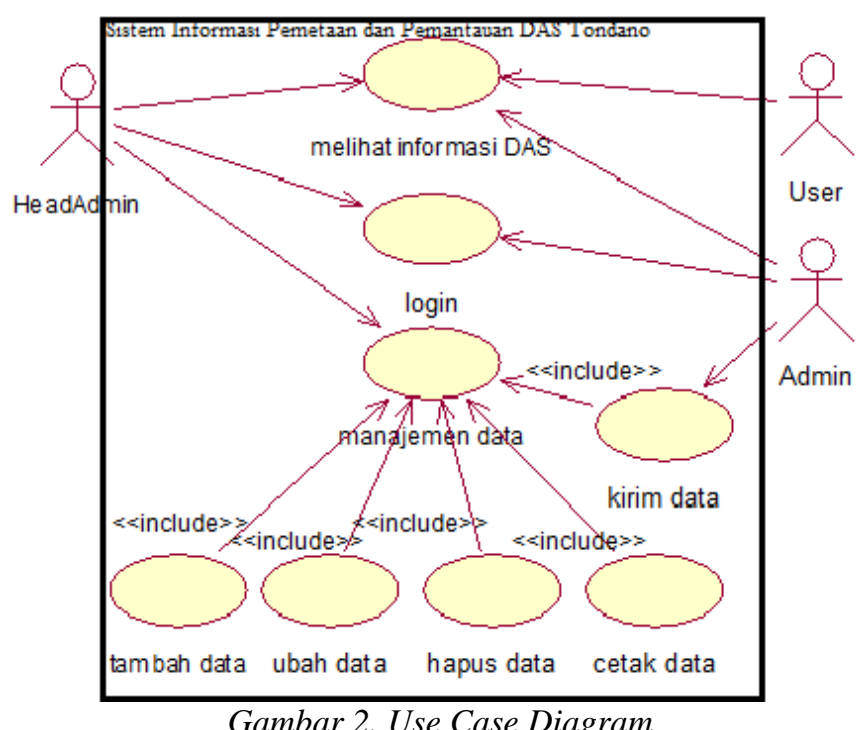

Gambar 2. Use Case Diagram 


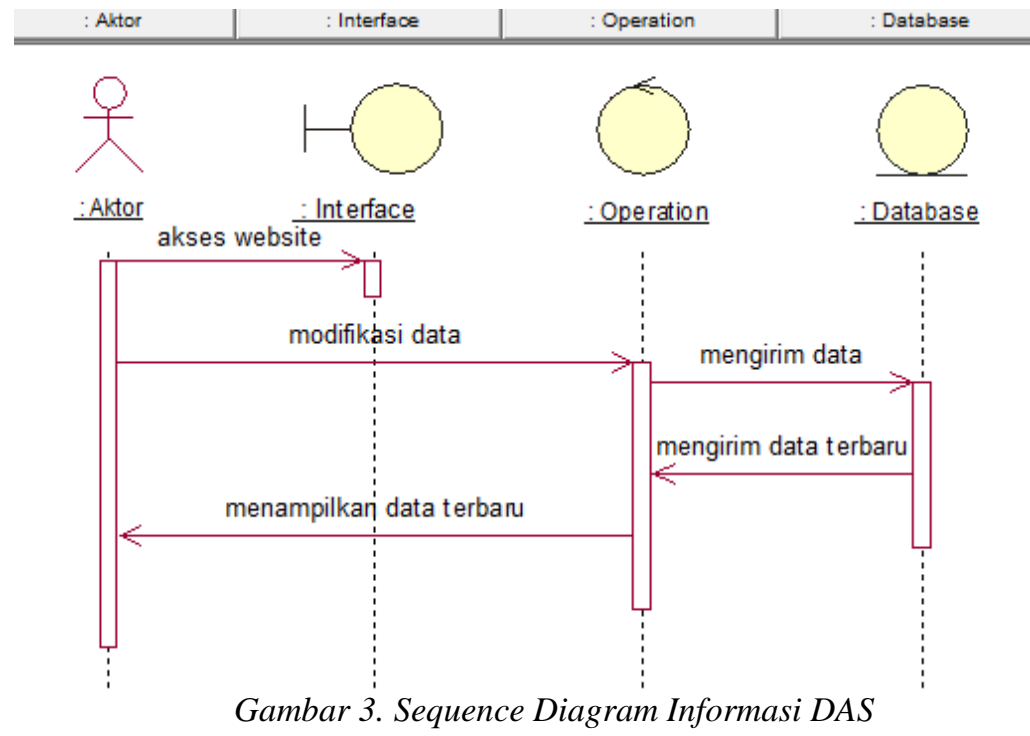

3. Tahap Transition

Tujuan dari tahap terakhir atau tahap transition ini yaitu menguji sistem dan mereview sistem.

\begin{tabular}{|c|c|c|c|c|}
\hline $\begin{array}{c}\text { Testing } \\
\text { Halaman }\end{array}$ & $\begin{array}{c}\text { Hasil Yang } \\
\text { Diharapkan }\end{array}$ & $\begin{array}{c}\text { Hasil Yang } \\
\text { Didapatkan }\end{array}$ & Keterangan & Solusi \\
\hline TambahData & $\begin{array}{l}\text { Sistem bisa } \\
\text { menambah Data } \\
\text { DAS }\end{array}$ & $\begin{array}{l}\text { Terjadi error saat } \\
\text { pemetaan lokasi } \\
\text { aliran sungai }\end{array}$ & Bermasalah & $\begin{array}{l}\text { Menghilangkan } \\
\text { beberapa } \\
\text { sintaks yang } \\
\text { tidak } \\
\text { dibutuhkan, yg } \\
\text { membuat } \\
\text { proses } \\
\text { TambahData } \\
\text { menjadi lambat }\end{array}$ \\
\hline
\end{tabular}

Tabel 2. Pengujian Sistem

\section{PEMBAHASAN}

Pada pembagian pembahasan, penulis akan menampilkan hasil jadi dari sistem yang telah dirancang, yaitu sebuah produk aplikasi berbasis web dengan menggunakan fitur SMS Gateway dan Google Maps sebagai pemetaan lokasinya. Berikut ini tahap-tahapannya:

Gambar dibawah ini (Gambar 4) adalah tampilan menu utama dalam perancangan ini. Dimana pengguna mendaftarkan nomor handphone apabila ingin mendapatkan informasi via SMS mengenai kondisi DAS Tondano di Kota Manado. 


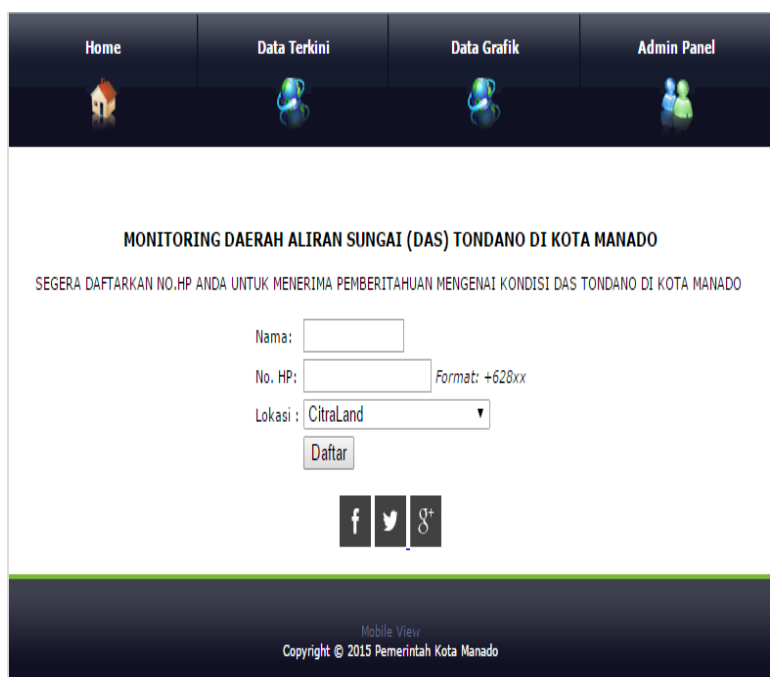

Gambar 4. Pendaftaran Nomor Handphone (Tampilan Menu Utama)

Gambar dibawah ini (Gambar 5) adalah tampilan pengiriman informasi DAS Tondano di Kota Manado menggunakan SMS yang dilakukan oleh petugas penjaga (Admin).
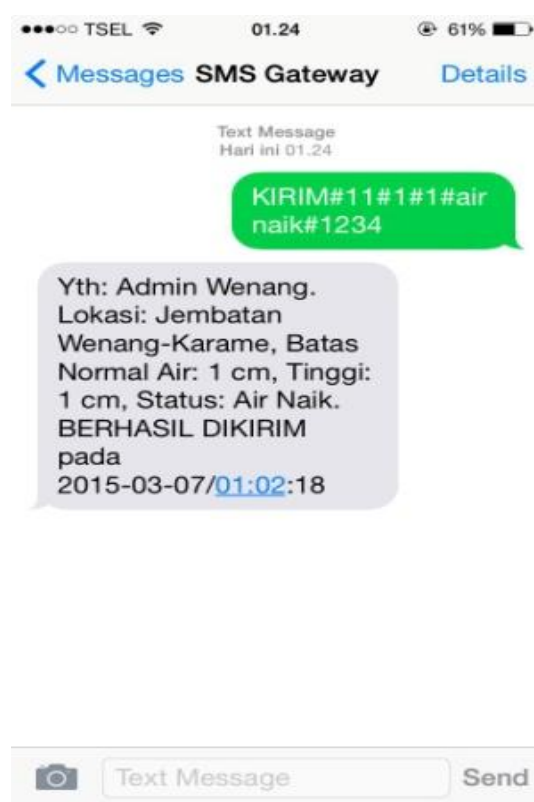

Gambar 5. Pengiriman Informasi DAS Menggunakan SMS Gateway

Gambar dibawah ini (Gambar 6) adalah tampilan pemantauan DAS Tondano di Kota Manado berbasis $w e b$. Dimana tampilan ini dapat dilihat oleh semua pengguna yang mengakses web tersebut dengan menggunakan koneksi internet. 


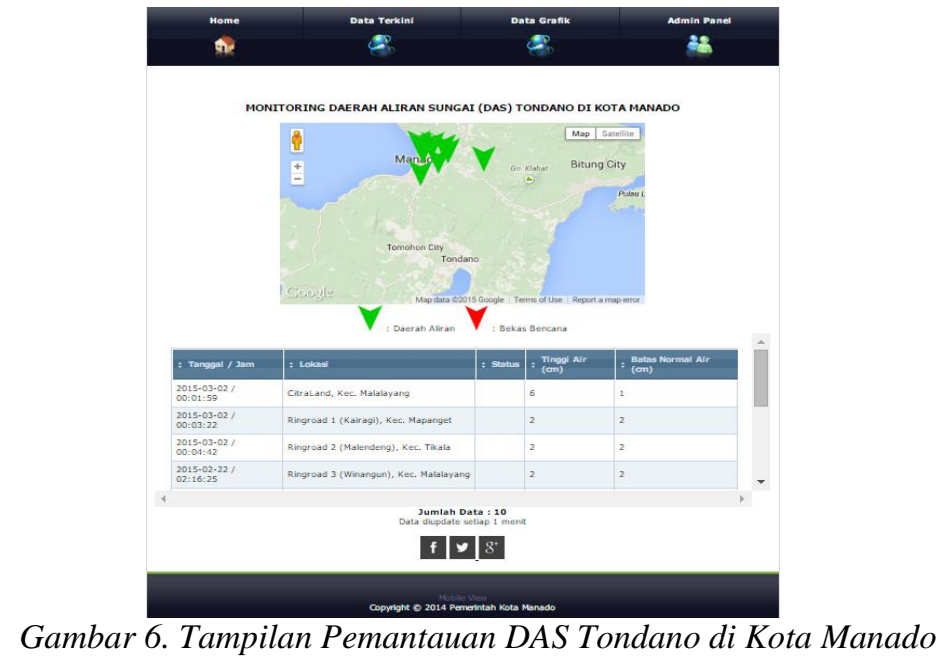

\section{PENUTUP}

5.1 Kesimpulan

Kesimpulan yang didapat:

a) Sistem informasi DAS Tondano di Kota Manado dapat berfungsi sebagai repository atau tempat penyimpanan data ketinggian air DAS Tondano, sehingga informasi bisa dipantau dan dibagikan kepada pengguna (seperti Pemerintah Kota Manado dan masyarakat umum).

b) Menggunakan metodologi DAD sebagai panduan dalam aktivitas pengembangan sistem informasi pemetaan dan pemantauan DAS Tondano di Kota Manado berbasis web dan mobile web, sehingga pengembangan dapat dilakukan dalam waktu relatif singkat dengan paradigma berorientasi objek dan menghasilkan aplikasi jadi.

\subsection{Saran}

Saran pengembangan sistem kedepannya:

a) Menggunakan Cloud Computing atau komputasi awan untuk mengintegrasi datanya melalui Google App Engine.

b) Titik-titik lokasi pemetaan dan pemantauan ini ditambah, misalnya bukan hanya di Kota Manado saja, tetapi sampai di pelosok-pelosok yang menjadi tempat DAS Tondano.

c) Menggunakan alat yang dapat bekerja untuk mengukur ketinggian DAS Tondano dan tidak melakukan pengiriman informasi melalui petugas, agar informasi yang dikirimkan dapat bekerja secara otomatis.

\section{DAFTAR RUJUKAN}

[1] BNPB. (2012). Update Banjir Bandang Manado (Online). Tersedia: http://www.bnpb.go.id/berita/1855/update-banjir-bandang-manado. [09 April 2015].

[2] Talukdar, Asoke K. Mobile Computing, 2E. Tata McGraw-Hill Education, 2010.

[3] Saleem, Muhammad, and Kyung-Goo Doh. "Generic Information System Using SMS Gateway." Computer Sciences and Convergence Information Technology, 2009. ICCIT'09. Fourth International Conference on. IEEE, 2009.

[4] Widhiarso, Yoni, and Berliana Kusuma Riasti. "Rancang Bangun Sistem Informasi Nilai Akademik Dan Presensi Siswa Berbasis SMS Gateway Pada SDN Tulakan III." IJNS-Indonesian Journal on Networking and Security 2.4 (2013).

[5] IBM, Advanced Disciplined Agile Delivery, IBM Corporation, 2011. 